Original article

\title{
Prevalent role of porosity and osteonal area over mineralization heterogeneity in the fracture toughness of human cortical bone
}

Mathilde Granke $e^{1,2,3}$, Alexander J Makowski ${ }^{1,2,3,4}$, Sasidhar Uppuganti ${ }^{1,2}$, Jeffry S Nyman ${ }^{1,2,3,4}$

${ }^{1}$ Department of Orthopaedics Surgery \& Rehabilitation, Vanderbilt University Medical Center, Nashville, TN 37232

${ }^{2}$ Center for Bone Biology, Vanderbilt University Medical Center, Nashville, TN 37232

${ }^{3}$ Department of Veterans Affairs, Tennessee Valley Healthcare System, Nashville, TN 37212

${ }^{4}$ Department of Biomedical Engineering, Vanderbilt University, Nashville, TN 37232

\author{
Contact: Jeffry S. Nyman \\ Medical Center East \\ South Tower, Suite 4200 \\ Nashville, TN 37232 \\ jeffry.s.nyman@vanderbilt.edu \\ office: (615) 936-6296 \\ fax: (615) 936-0117
}

Word count: 3893

Key Words: fracture toughness, heterogeneity, mineralization, porosity, microstructure 


\begin{abstract}
Changes in the distribution of bone mineralization occurring with aging, disease, or treatment have prompted concerns that alterations in mineralization heterogeneity may affect the fracture resistance of bone. Yet, so far, studies assessing bone from hip fracture cases and fracture-free women have not reached a consensus on how heterogeneity in tissue mineralization relates to skeletal fragility. Owing to the multifactorial nature of toughening mechanisms occurring in bone, we assessed the relative contribution of heterogeneity in mineralization to fracture resistance with respect to age, porosity, and area fraction of osteonal tissue. The latter parameters were extracted from quantitative backscattered electron imaging of human cortical bone sections following R-curve tests of single-edge notched beam specimens to determine fracture toughness properties. Microstructural heterogeneity was determined as the width of the mineral distribution (bulk) and as the sill of the variogram (local). In univariate analyses of measures from 62 human donors (21 to 101 years), local but not bulk heterogeneity as well as pore clustering negatively correlated with fracture toughness properties. With age as covariate, heterogeneity was a significant predictor of crack initiation, though local had a stronger negative contribution than bulk. When considering all potential covariates, age, cortical porosity and area fraction of osteons explained up to $50 \%$ of the variance in bone's crack initiation toughness. However, including heterogeneity in mineralization did not improve upon this prediction. The findings of the present work stress the necessity to account for porosity and microstructure when evaluating the potential of matrix-related features to affect skeletal fragility.
\end{abstract}

\title{
$1 \quad$ 1. Introduction
}

2 The fracture resistance of bone does not solely depend on the quantity of bone, or bone mineral

3 density, but also on the integrity of the bone tissue (Donnelly et al., 2014). In particular, owing to 
4 its hierarchical organization, bone is able to resist fracture through the combination of multiple

5 toughening mechanisms that interact at several length scales. For example, interfibrillar sliding at

6 the nanoscale allows the mineralized collagen fibrils to deform without failing, while osteons on

7 the order of hundreds of microns create natural barriers to the propagation of cracks through bone

8 tissue (O'Brien et al., 2003; Ural and Vashishth, 2014). With aging and disease progression,

9 changes can occur at any of the hierarchical levels of organization, thereby lowering the fracture

10 resistance of bone (e.g., accumulation of non-enzymatic collagen crosslinks impeding

11 interfibrillar sliding). Complicating the clinical assessment of fracture resistance or fracture risk,

12 heterogeneity exists at the multiple length scales of organization, but not all heterogeneity may

13 significantly contribute to the age-related loss of fracture resistance.

14 Investigations of fracture processes in material science indicate that microstructural

15 heterogeneity (i.e., the spatial variation of compositional properties in a material) improves

16 resistance to fracture: crack propagation is straight in a homogenous material with less energy

17 dissipation while it is tortuous deflecting at interfaces in a heterogeneous material, thereby

18 requiring more energy to grow (Dimas et al., 2014; Hossain et al., 2014). Changes in bone

19 metabolism associated with diseases or drug treatment are known to significantly affect the

20 distribution of bone mineralization at the micron length scale (Roschger et al., 2008). In this

21 context, a loss in heterogeneity in mineralization has been posited as a possible factor

22 contributing to an increase in fracture risk (Ettinger et al., 2013). However, in the current

23 literature, there is a lack of consensus on how heterogeneity in tissue mineralization relates to

24 skeletal fragility. Indeed, heterogeneity in mineralization at the micro-structural level was found

25 either to be greater (Bousson et al., 2011) or lower (Gourion-Arsiquaud et al., 2013; Milovanovic

26 et al., 2014) in treatment naïve, hip fracture cases compared to fracture-free women. The 
27 inconsistency of these results highlights the need to account for other contributing factors to 28 conclusively state that bone fragility is directly related to the distribution of tissue mineralization.

Among the factors that contribute to skeletal fragility, vascular porosity is greater in

30 patients with a history of fracture compared to non-fracture controls (Ahmed et al., 2015; Bala et

31 al., 2014; Bell et al., 1999; Milovanovic et al., 2014; Shigdel et al., 2015) or in bone specimens

32 with lower fracture toughness properties, as determined from mechanical tests of cadaveric tissue

33 (Granke et al., 2015; Yeni et al., 1997). Moreover, image analysis of bone cross-sections of the

34 femoral neck suggests that greater cortical porosity in fragile bone may result from the merging

35 of spatially clustered remodeling osteons (Bell et al., 2000; Jordan et al., 2000). Therefore, not

36 only the extent but also the spatial distribution of porosity may decrease the fracture resistance of

37 bone, a phenomenon described for porous media (Bilger et al., 2005).

38 To date, the question of whether heterogeneity mineralization affects bone's resistance to

39 fracture remains undetermined for two reasons. First, published data is confined to comparing

40 tissue composition between fracture and control cases, but to date, no studies have attempted to

41 relate heterogeneity in mineralization and the mechanical properties of cortical bone. Second,

42 most studies investigating associations between tissue composition and fracture status or risk do

43 not adjust for other microstructural features (i.e., porosity or bone volume fraction). Given the

44 possible contribution of age, porosity, and tissue microstructure to skeletal fragility, we aimed to

45 determine whether microstructural heterogeneity in mineralization significantly explains bone's

46 ability to resist fracture after adjusting for these factors. To address this, we analyzed cross-

47 sections of human cortical bone specimens for which fracture toughness properties had been

48 previously determined (Granke et al., 2015). Upon imaging these cross-sections by quantitative

49 backscattered electron imaging (qBEI), image processing techniques quantified lacunar and 
50 vascular porosities, pore clustering, population and local heterogeneity in mineralization, as well

51 as area fraction of osteonal tissue.

\section{2. Material and methods}

54 The preparation of the mechanical specimens and measurement methods are extensively

55 described in Granke et al. (2015) and briefly summarized herein. Femurs from sixty-two human

56 donors (30 male, age $=63.5 \pm 23.7$ [21 -98] years and 32 female, age $=64.4 \pm 21.3$ [23-101]

57 years) were obtained from the Musculoskeletal Transplant Foundation (Edison, NJ), the

58 Vanderbilt Donor Program (Nashville, TN), and the National Disease Research Interchange

59 (Philadelphia, PA) and stored fresh-frozen. Single-sedge notched beam (SENB) specimens (span

$60 \mathrm{x}$ thickness $\mathrm{x}$ width $\sim 20 \times 2.5 \times 5.0 \mathrm{~mm}^{3}$ ) were machined from the lateral quadrant of each

61 femoral mid-shaft $(\mathrm{N}=62)$. After imaging the notched region with micro-computed tomography

$62(\mu \mathrm{CT})$ at a $5 \mu \mathrm{m}$ voxel size (Granke et al., 2015) to determine vascular porosity, a progressive,

63 loading/partial unloading/reloading scheme in a three-point bending configuration was used to

64 initiate and propagate a crack from the micro-notch through the cortical bone such that crack

65 extension was perpendicular to the osteonal direction. A non-linear fracture mechanics approach

66 based on the analysis of the resulting R-curve (J-integral vs. crack length) provided the resistance

67 (elastic plus plastic contributions) to initiate $\left(K_{\text {init }}\right)$ and propagate $\left(K_{\text {grow }}\right)$ a crack from the notch

68 as well as the energy dissipated during fracture $(J)$ (ASTM Standard E1820-15a, 2015). $K_{\text {grow }}$

69 could not be calculated for specimens that exhibit highly brittle behavior, which was the case for

7011 specimens out of 62 . Following mechanical testing, the specimens were stored in phosphate-

71 buffered saline at $-20^{\circ} \mathrm{C}$ until the next phase of the experimental protocol.

72 2.1 Quantitative backscattered electron imaging (qBEI) 


\section{2.1.1 Specimens preparation and image acquisition}

74 A cross-section $(\sim 2.5 \mathrm{~mm} \times 4.5 \mathrm{~mm})$ was cut adjacent to the fracture line (Fig.1), ground on 75 successive grits (1200 to 4000) of wet silicon carbide paper, and polished on synthetic cloth with $760.05 \mu \mathrm{m}$ aluminum oxide suspension (MasterPrep, Buehler, Lake Bluff, IL). Upon drying for 77 several days in a vacuum desiccator at room temperature, the samples were mounted on 78 aluminum stubs with double-sided carbon tape together with pure aluminum and carbon 79 standards for calibration (EMS, Hatfield PA) (Fig.1). The surface of the specimen was imaged by 80 qBEI using a Quanta FEG 250 ESEM (FEI Company, Hillsboro, Oregon, USA) equipped with a 81 low-voltage, high-contrast backscattered electron detector. Digital images from the bone cross82 section and calibration materials were acquired using the same settings (high vacuum mode, 83 acceleration voltage of $20 \mathrm{kV}$, working distance of $15 \mathrm{~mm}$, scan speed of $100 \mathrm{sec} / \mathrm{frame}$ ). Contrast 84 and brightness were adjusted so that the mean grey levels of the backscattered signals from 85 carbon and aluminum reached 25 and 225 , respectively. In order to cover the entire surface of the 86 cross-section, four to six images $\left(2 \times 2.5 \mathrm{~mm}^{2}\right)$ were collected at 50x magnification with a $1.2 \mu \mathrm{m}$

87 pixel resolution, merged to a single image using Photoshop ${ }^{\circledR}$ CS6 (Adobe Systems Inc., San Jose,

88 CA, USA), and Gauss-filtered $(\sigma=1)$ (Fig.1). Although the specimens were not carbon-coated, 89 electron charging did not build up as demonstrated by imaging the same bone surface repeatedly 90 over the course of 15 minutes (Supplementary Fig.1) and by imaging the same specimen before 91 and after carbon coating (Supplementary Fig.2). All the following post-processing analyses were 92 implemented in MATLAB ${ }^{\circledR}$ (The Mathworks Inc., Natick, MA, USA).

$94 \quad 2.1 .2$ Porosity analysis

95 A semi-automated procedure was used to segment the pores from the bony matrix (Fig.2A). A 96 porosity mask was first created using Otsu's method (Otsu, 1979). Any surface contaminants 
97 (e.g., dust particles) and large cracks were manually removed from the porosity mask using

98 Photoshop CS6 (Adobe Systems, Inc., San Jose, CA). Pores with an area larger than $100 \mu \mathrm{m}^{2}$

99 were assigned to vascular porosity (including Haversian canals, Volkmann's canals, resorption

100 cavities) or to lacunar porosity otherwise (Fig.2B).

101 The heterogeneity in the spatial distribution of the vascular porosity was analyzed using

102 Voronoi diagrams (Aurenhammer, 1991). The sides of the Voronoi polygons are located at mid-

103 distance from neighboring pores (Fig.2C). The area of each polygon was determined without

104 excluding the pore area (black region in Fig.2C). High coefficient of variation for the individual

105 areas of the Voronoi polygons ( $V O R c v$ ) indicates a heterogeneous, clustered distribution of pores.

106

$107 \quad$ 2.1.3 Mineralization heterogeneity

108 Given that the backscattered signal intensity is proportional to the average atomic number of a

109 material, the mineral phase essentially dictates the qBEI intensity. Histograms of the gray-levels

110 in the qBEI images provided the most frequently occurring gray value (BSEpeak) and the width

111 at half maximum (BSEwidth) describing the variation in degree of mineralization over the cross-

112 section $\left(\sim 10 \mathrm{~mm}^{2}\right)$ (Fig.3B).

113 The width of the histogram does not inform on the clustering of the heterogeneities

114 (Supplementary Fig.3). Therefore, an additional analysis involved computing experimental

115 variograms, which were used to describe the local inhomogeneity of tissue mineralization.

116 Descriptions of calculating variograms can be found in previous bone studies that described the

117 inhomogeneity in tissue elastic properties from maps of nanoindentation modulus (Dong et al.,

118 2010) and the inhomogeneity in areal bone mineral density maps from hip scans by dual-energy

119 X-ray absorptiometry (Dong et al., 2015). In the present study, an isotropic variogram of the 120 qBEI image was built by computing $\gamma(h)$, the mean squared gray-level differences between pixels 
121 separated by a distance $h$ spanning from 1 to $250 \mu \mathrm{m}$. Upon fitting the experimental variogram

122 with an exponential function,

$$
\gamma(h)=c_{0}+c\left(1-e^{-\frac{3 h}{L}}\right)
$$

123 the asymptote of the variogram $\left(c+c_{0}\right)$ or sill provided a measure of the semi-variance in

124 mineralization over a length scale of $250 \mu \mathrm{m}$ (Fig.3C). This length scale was chosen because it is

125 small enough to represent the variance in mineralization at a local scale (i.e., the scale of an

126 osteon) and it is large enough to ensure that pixels would not be auto-correlated (i.e., once the

127 variogram levels off).

128

$129 \quad 2.1 .4$ Microstructure analysis

130 Based on differences in gray levels, osteonal and interstitial tissues were manually segmented 131 within a sub-region $(1.5 \mathrm{~mm} \times 1.5 \mathrm{~mm})$ at the center of each qBEI image (Fig.4B) using an 132 interactive tablet monitor (Wacom Technology Co., Vancouver, WA). Manual segmentation is 133 commonly used to distinguish osteonal from interstitial tissue (Bernhard et al., 2013; Tommasini

134 et al., 2008; Wachter et al., 2002; Wang et al., 2015) and increasing the image contrast for this 135 step made the segmentation unambiguous. Area fraction of osteonal tissue (OstAr) with respect to 136 the total area of the sub-region was computed for each sub-region. BSEpeak was computed for 137 both the distribution of osteonal and interstitial tissue, respectively. Contrast in mineralization in 138 this sub-region was evaluated as the ratio of the interstitial BSEpeak to the osteonal BSEpeak 139 (IOratio). 
142 In a preliminary analysis, we verified that the pores examined with qBEI from neighboring cross-

143 sections were representative of the pores within the region where the crack actually propagated (a

144 few millimeters away in the osteon direction, Fig.1). The vascular porosity derived from qBEI

145 images (VasPor) was therefore compared to the vascular porosity of the notched region imaged

146 with $\mu \mathrm{CT}$ (Ct.Po) using the equation and correlation coefficient of the linear fit between these

147 two quantities.

148 Upon running multiple linear regressions with age and gender as covariates on all

149 parameters reported (i.e. including properties related to fracture toughness, porosity,

150 mineralization, and microstructure), gender was only significant for $K_{\text {init }}$ (Supplementary Table

151 1). Further analysis revealed that this association between gender and $K_{\text {init }}$ was driven by two

152 particular specimens as the $\mathrm{p}$-value of gender was greater than 0.082 after excluding these donors

$153(\mathrm{~N}=60$ instead of $\mathrm{N}=62)$. Therefore, age but not gender was included as a covariate in subsequent

154 regression analyses.

155 Statistical analyses were performed on bootstrapped data (1000 replicates) to account for

156 the non-normality of most parameters (Shapiro-Wilk test). Pearson correlation coefficients were

157 used to assess the linear dependence of fracture toughness parameters on potential explanatory

158 variables related to age, porosity, mineral heterogeneity, and microstructure (Table 1). Potential

159 predictors (age and parameters related to porosity, mineralization, and microstructure) with weak

160 correlations $(\mathrm{r}<0.55$, Supplemental Table 2$)$ and their interactions were included as independent

161 explanatory variables in multiple linear regressions. For each model, backward stepwise

162 elimination was used to remove non-significant terms until obtaining a combination of variables

163 that all significantly explained the variance in the fracture toughness properties (Table 2). 
164 Statistical significance of a predictor was reached when the associated p-value was less than 0.05.

165 Analyses were performed using STATA 12 (StataCorp LP, College Station, TX).

167 3. Results

168 The vascular porosity estimated from qBEI images of a neighboring cross-section strongly

169 correlated with the porosity of the material in the crack path as assessed with $\mu \mathrm{CT}$ prior to

170 mechanical testing $\left(\mathrm{R}^{2}=87.2 \%\right)$. While the slope of the linear fit between VasPor and Ct.Po was

171 not significantly different from unity, the intercept was significantly different from zero: qBEI

172 yielded higher values of porosity compared to $\mu \mathrm{CT}$, possibly because of the lower resolution of

173 the latter technique (Supplementary Fig.4).

174 Among all reported parameters, vascular porosity showed the highest, negative correlation

175 with crack initiation toughness $\left(K_{\text {init }}\right)$ and the energy dissipated $(J)$ during fracture (Table 1$)$. As

176 higher porosity was associated with more clustered pores (Supplementary Table 2), a more

177 heterogeneous spatial distribution of porosity was also related to a decrease in the aforementioned

178 fracture toughness properties (Table 1). Lacunar porosity was positively correlated with fracture

179 toughness properties (Table 1). However, this relationship may not be causal but rather reflects

180 the fact that both lacunar porosity and fracture toughness properties decrease with age. Indeed,

181 the correlations between lacunar porosity and fracture toughness properties were not significant

182 when adding age as a covariate.

183 Among the parameters characterizing the distribution of mineralization within the matrix,

184 the average degree of mineralization (BSEPeak), bulk or population heterogeneity in tissue 185 mineralization (BSEwidth) and mineralization ratio between interstitial and osteonal tissue 186 (IOratio) did not correlate with any of the fracture toughness properties (Table 1). However, local 
187 heterogeneity ( $\mathrm{sill}$ ) as derived from the variogram analysis was greater in bone specimens with a

188 lower resistance to crack initiation (Kinit) and a reduced ability to dissipate energy (J) (Table 1$)$.

189 With respect to the microstructure, bone specimens having a greater area fraction of

190 osteonal tissue (OstAr) tended to have greater resistance to crack initiation and propagation

191 (Table 1 and Fig. 5). Microstructure, local heterogeneity in mineralization, and vascular porosity

192 each remained significant predictors of crack initiation toughness and energy dissipated during

193 fracture after adjusting for age. Cortical porosity had a stronger contribution to Kinit than age,

194 whereas age had a stronger contribution to Kinit than the heterogeneity parameters (BSEwidth

195 and sill) and OstAr (standardized coefficients, Table 2). The combination that best explained the

196 age-related variance in fracture toughness properties included age, cortical porosity, and the

197 microstructural feature related to cement lines (Table 2 and Fig.5). Most notably, none of the

198 parameters describing the heterogeneity in mineralization (BSEwidth, sill or IOratio) combined

199 with either VasPor or OstAr improved the prediction of fracture toughness.

\section{4. Discussion}

202 Changes in the distribution of bone mineralization occurring with aging, disease, or treatment 203 have prompted concerns that alterations in mineralization heterogeneity may affect the fracture 204 resistance of bone. Owing to the multifactorial nature of toughening mechanisms occurring in 205 bone, we aimed to put into perspective the relative contribution of heterogeneity in mineralization 206 to bone fracture resistance in comparison to other important factors. Our results obtained from 62 207 human donors spanning the age of adulthood (21 years to 101 years) suggest that changes in 208 porosity and microstructure overwhelm the contribution of heterogeneity in tissue mineralization 209 to explain the age-related loss in fracture toughness of human cortical bone. 
211 Vashishth, 2012; Tang and Vashishth, 2011; Ural and Vashishth, 2007), our data confirmed the

212 detrimental effect of an increase in intracortical porosity on bone's fracture toughness: the matrix

213 of highly porous tissue presents higher local strains, facilitating the initiation of cracks which

214 then propagate faster through the pores. In addition, we found that a more clustered distribution

215 of porosity was negatively correlated with the three fracture toughness properties of human

216 cortical bone. However, because greater vascular porosity was associated with a more clustered

217 distribution of pores $(r=0.86$, supplemental Table 2$)$, the pore clustering did not help improve

218 the prediction of fracture toughness properties when accounting for intra-cortical porosity.

219 In addition to porosity, bone microstructure (i.e., the compartmentalization of the matrix

220 in osteonal and interstitial tissue) possibly plays an important role in bone's ability to resist

221 fracture as cement lines and lamellar pattern in osteons affect the propagation of cracks in bone

222 tissue (Chan et al., 2009; Ural and Mischinski, 2013; Zioupos, 2001). Our results suggest that an

223 overall greater osteonal area fraction increases bone's fracture toughness properties, even when

224 including the contribution of porosity. This suggests that the presence of relatively newer tissue

225 within osteons and cement lines favor fracture resistance. Interestingly, OstAr was the only

226 selected property to correlate with crack propagation toughness supporting the importance of

227 cement lines to crack deflection, but significance of this relationship was lost when age was

228 included as covariate. Histological studies of human bone have shown that linear microcracks

229 preferentially form and propagate within interstitial bone and are arrested by the cement lines and

230 lamellar interfaces of osteons (Diab and Vashishth, 2007): this would explain why a greater

231 osteonal area fraction favors bone's resistance to fracture.

232 Even though material heterogeneity is thought to promote toughening mechanisms in 233 composites like bone, population and local heterogeneity in tissue mineralization were negatively 
234 correlated with crack initiation toughness and energy dissipated during fracture when age was

235 included as covariate (Table 2); and notably, a local measure (sill) was a better predictor than a

236 bulk measure (BSEwidth) of heterogeneity. This is consistent with findings reporting weak,

237 negative correlations between heterogeneity in microhardness (mean ratio of interstitial to

238 osteonal areas) and fracture toughness in which the crack propagation was parallel to the osteonal

239 axis (Phelps et al., 2000) or fatigue strength of cortical bone in tension (Zioupos et al., 2008) and

240 supports the notion that heterogeneity at the length scale of $\sim 200 \mu \mathrm{m}$ can promote crack

241 formation by concentrating strains within the bone matrix. Nonetheless, the prevailing finding of

242 this work is that microstructural heterogeneity in tissue mineralization did not help explain

243 changes in fracture toughness properties after accounting for age, porosity and microstructure.

244 This is in agreement with the findings from the largest tissue composition study to date (Boskey

245 et al., 2016) showing that heterogeneity in various outcomes (mineral-to-matrix ratio, carbonate-

246 to-phosphate ratio, crystallinity, acid phosphate substitution, collagen maturity) at the micron

247 length scale is not significantly different between female subjects with and without a fracture,

248 when controlling for age and areal bone mineral density (60 subjects in each group).

249 The present study brings new insights into interpreting the effect of treatment-related 250 changes at the tissue level on bone's fracture resistance. In particular, the association between the

251 occurrence of atypical femoral fractures and the long-term use of bisphosphonates, established as

252 the first-line therapy for osteoporosis, has promulgated the idea that the reduced microstructural

253 heterogeneity in mineralization observed in treated patients (Donnelly et al., 2012; Roschger et

254 al., 2008; Zoehrer et al., 2006) may contribute to these rare, but adverse events (Ettinger et al.,

255 2013). Our results suggest that the significant reduction in cortical porosity that follows anti-

256 resorptive treatment (Borah et al., 2010; Misof et al., 2014; Zebaze et al., 2014) would far

257 outweigh the shift toward a more homogenous tissue mineralization. Moreover, that shift back to 
258 a narrower distribution may itself promote fracture resistance as menopause-related increase in

259 remodeling likely leads to excessive heterogeneity (Roschger et al., 2008), which could decrease

260 crack initiation toughness (Table 2). Notably, bisphosphonates remain effective in reducing

261 fracture risk for a vast majority of patients after years of use (Chen and Sambrook, 2012; Eriksen

262 et al., 2014), though drug holidays may minimize the impact of suppressed remodeling on the

263 accumulation of glycation-mediated, non-enzymatic crosslinks. Generally, the present study

264 points out that difficulty in establishing a causal relationship between tissue mineralization and

265 skeletal fragility if underlying changes in porosity are ignored.

266 This study is limited to a few features of cortical bone which only capture up to $50 \%$ of

267 the variance in fracture toughness properties highlighting the need to investigate alternative

268 toughening mechanisms to fully comprehend bone's fracture resistance. The favorable role of

269 osteonal tissue (Table 2) likely pertains to its concentric lamellar structure where layers of

270 mineralized collagen fibers are laid with changing orientations (Giraud-Guille, 1988), requiring

271 more energy for a crack to penetrate through this composite structure. Indeed, the mechanical

272 inhomogeneity at the lamellar scale produced by different collagen fiber orientation has been

273 described as an important toughening mechanism (Katsamenis et al., 2015) in addition to the

274 orientation of the collagen fibrils relative to the crack direction (Peterlik et al., 2006). This

275 suggests that heterogeneity in collagen orientation rather than in tissue mineralization could be a

276 more important determinant of bone fracture toughness. It remains to be seen whether alterations

277 in collagen-related properties (e.g., crosslinking profile, amount of collagen) would significantly

278 contribute to bone's integrity in addition to cortical porosity. The non-mineral component of the

279 matrix may actually be a more important contributor to fracture toughness than mineralization as

280 computational models suggest that heterogeneity in plastic rather than elastic properties plays a

281 major role in promoting energy dissipation at the sub-micron scale (Yao et al., 2011). Moreover, 
282 material heterogeneity at length scales smaller than a micron may promote fracture toughness of

283 cortical bone as suggested by computational modeling (Tai et al., 2007). Finally, numerous

284 mechanisms at the nanoscale also participate in providing bone its ability to resist fracture

285 (Thurner and Katsamenis, 2014), including non-enzymatic collagen cross-links (Poundarik et al.,

286 2015), non-collagenous proteins (Katsamenis et al., 2013; Poundarik et al., 2012), bound water

287 (Granke et al., 2015), and microdamage (Norman et al., 1998; Seref-Ferlengez et al., 2015;

288 Zioupos, 2001).

289 Another limitation of the present study was that specimens came from the femoral mid-

290 shaft, which is not a typical fracture site. However, it is reasonable to assume that aging, diseases,

291 or drug therapy would affect the skeleton in a systemic manner, in other words, changes in

292 porosity and mineralization occurring at the femoral mid-shaft would also occur at the femoral

293 neck. In a recent study, Abraham et al. (2015) showed that porosity, microindentation, and

294 collagen crosslinks measures at the tibia could predict fragility of the femoral neck.

295 In summary, assessing the microstructure of cortical bone specimens from 62 human

296 donors, we found that age, cortical porosity and osteonal fraction explained up to $50 \%$ of the

297 variance in bone's fracture toughness properties and that including microstructural heterogeneity

298 in tissue mineralization did not improve upon this prediction. Moreover, this heterogeneity is

299 negatively correlated with crack initiation toughness. The findings of the present work stress the

300 necessity to account for porosity and microstructure when evaluating the potential of matrix-

301 related features to affect skeletal fragility.

302

303 Acknowledgements

304 The National Institute of Arthritis and Musculoskeletal and Skin Diseases of the National

305 Institutes of Health (NIH) under AR063157 primarily funded this work. The micro-computed 
306 tomography scanner was supported by the National Center for Research Resources

307 (1S10RR027631) and matching funds from the Vanderbilt Office of Research. Additional

308 funding to perform the work was received from the Department of Veterans Affairs, Veterans

309 Health Administration, Office of Research and Development (1I01BX001018) and the National

310 Science Foundation (1068988) to collect specimens and develop the fracture toughness testing

311 protocol. SEM imaging was performed through the use of the VUMC Cell Imaging Shared

312 Resource (supported by NIH grants CA68485, DK20593, DK58404, DK59637 and EY08126).

\section{References}

317 Abraham, A.C., Agarwalla, A., Yadavalli, A., McAndrew, C., Liu, J.Y., Tang, S.Y., 2015. 318 Multiscale Predictors of Femoral Neck In Situ Strength in Aging Women: Contributions of 319 BMD, Cortical Porosity, Reference Point Indentation, and Nonenzymatic Glycation. J Bone 320 Miner Res 30, 2207-2214.

321 Ahmed, L.A., Shigdel, R., Joakimsen, R.M., Eldevik, O.P., Eriksen, E.F., Ghasem-Zadeh, A., 322 Bala, Y., Zebaze, R., Seeman, E., Bjornerem, A., 2015. Measurement of cortical porosity of the 323 proximal femur improves identification of women with nonvertebral fragility fractures. 324 Osteoporos Int 26, 2137-2146.

325 ASTM Standard E1820-15a, 2015. Standard Test Method for Measurement of Fracture 326 Toughness.

327 Aurenhammer, F., 1991. Voronoi diagrams - A survey of a fundamental geometric data structure. 328 ACM Comput. Surv. 23, 345-405.

329 Bala, Y., Zebaze, R., Ghasem-Zadeh, A., Atkinson, E.J., Iuliano, S., Peterson, J.M., Amin, S., 330 Bjornerem, A., Melton, L.J., 3rd, Johansson, H., Kanis, J.A., Khosla, S., Seeman, E., 2014. 331 Cortical porosity identifies women with osteopenia at increased risk for forearm fractures. J Bone 332 Miner Res 29, 1356-1362.

333 Bell, K.L., Loveridge, N., Jordan, G.R., Power, J., Constant, C.R., Reeve, J., 2000. A novel 334 mechanism for induction of increased cortical porosity in cases of intracapsular hip fracture. 335 Bone 27, 297-304. 

differences in cortical porosity in the fractured femoral neck. Bone 24, 57-64.

338 Bernhard, A., Milovanovic, P., Zimmermann, E.A., Hahn, M., Djonic, D., Krause, M., Breer, S., 339 Puschel, K., Djuric, M., Amling, M., Busse, B., 2013. Micro-morphological properties of osteons 340 reveal changes in cortical bone stability during aging, osteoporosis, and bisphosphonate treatment 341 in women. Osteoporos Int 24, 2671-2680.

342 Besdo, S., Vashishth, D., 2012. Extended Finite Element models of intracortical porosity and heterogeneity in cortical bone. Comp Mater Sci 64, 301-305.

344 Bilger, N., Auslender, F., Bornert, M., Michel, J.-C., Moulinec, H., Suquet, P., Zaoui, A., 2005. 345 Effect of a nonuniform distribution of voids on the plastic response of voided materials: a 346 computational and statistical analysis. Int J Solids Struct 42, 517-538.

347 Borah, B., Dufresne, T., Nurre, J., Phipps, R., Chmielewski, P., Wagner, L., Lundy, M., 348 Bouxsein, M., Zebaze, R., Seeman, E., 2010. Risedronate reduces intracortical porosity in women 349 with osteoporosis. J Bone Miner Res 25, 41-47.

350 Boskey, A.L., Donnelly, E., Boskey, E., Spevak, L., Ma, Y., Zhang, W., Lappe, J., Recker, R.R., 351 2016. Examining the Relationships between Bone Tissue Composition, Compositional Heterogeneity and Fragility Fracture: A Matched Case Controlled FTIRI Study. J Bone Miner Res 31, 1070-1081.

357 Chan, K.S., Chan, C.K., Nicolella, D.P., 2009. Relating crack-tip deformation to mineralization 358 and fracture resistance in human femur cortical bone. Bone 45, 427-434.

359 Chen, J.S., Sambrook, P.N., 2012. Antiresorptive therapies for osteoporosis: a clinical overview. 360 Nature reviews. Endocrinology 8, 81-91.

361 Diab, T., Vashishth, D., 2007. Morphology, localization and accumulation of in vivo 362 microdamage in human cortical bone. Bone 40, 612-618.

363 Dimas, L.S., Giesa, T., Buehler, M.J., 2014. Coupled continuum and discrete analysis of random 364 heterogeneous materials: Elasticity and fracture. J Mech Phys Solids 63, 481-490.

365 Dong, X.N., Luo, Q., Sparkman, D.M., Millwater, H.R., Wang, X., 2010. Random field 366 assessment of nanoscopic inhomogeneity of bone. Bone 47, 1080-1084.

367 Dong, X.N., Pinninti, R., Lowe, T., Cussen, P., Ballard, J.E., Di Paolo, D., Shirvaikar, M., 2015. 368 Random field assessment of inhomogeneous bone mineral density from DXA scans can enhance 369 the differentiation between postmenopausal women with and without hip fractures. J Biomech 370 48, 1043-1051. 
371 Donnelly, E., Lane, J.M., Boskey, A.L., 2014. Research perspectives: The 2013 AAOS/ORS research symposium on Bone Quality and Fracture Prevention. J Orthop Res 32, 855-864.

373 Donnelly, E., Meredith, D.S., Nguyen, J.T., Gladnick, B.P., Rebolledo, B.J., Shaffer, A.D., 374 Lorich, D.G., Lane, J.M., Boskey, A.L., 2012. Reduced cortical bone compositional heterogeneity with bisphosphonate treatment in postmenopausal women with intertrochanteric and subtrochanteric fractures. J Bone Miner Res 27, 672-678.

377 Eriksen, E.F., Diez-Perez, A., Boonen, S., 2014. Update on long-term treatment with 378 bisphosphonates for postmenopausal osteoporosis: a systematic review. Bone 58, 126-135.

379 Ettinger, B., Burr, D.B., Ritchie, R.O., 2013. Proposed pathogenesis for atypical femoral 380 fractures: lessons from materials research. Bone 55, 495-500.

381 Giraud-Guille, M.M., 1988. Twisted plywood architecture of collagen fibrils in human compact 382 bone osteons. Calcif Tissue Int 42, 167-180.

383 Gourion-Arsiquaud, S., Lukashova, L., Power, J., Loveridge, N., Reeve, J., Boskey, A.L., 2013. 384 Fourier transform infrared imaging of femoral neck bone: reduced heterogeneity of mineral-to385 matrix and carbonate-to-phosphate and more variable crystallinity in treatment-naive fracture 386 cases compared with fracture-free controls. J Bone Miner Res 28, 150-161.

387 Granke, M., Makowski, A.J., Uppuganti, S., Does, M.D., Nyman, J.S., 2015. Identifying novel 388 clinical surrogates to assess human bone fracture toughness. J Bone Miner Res 30, 1290-1300.

389 Hossain, M.Z., Hsueh, C.J., Bourdin, B., Bhattacharya, K., 2014. Effective toughness of 390 heterogeneous media. J Mech Phys Solids 71, 15-32.

391 Jordan, G.R., Loveridge, N., Bell, K.L., Power, J., Rushton, N., Reeve, J., 2000. Spatial 392 clustering of remodeling osteons in the femoral neck cortex: a cause of weakness in hip fracture? 393 Bone 26, 305-313.

394 Katsamenis, O.L., Chong, H.M., Andriotis, O.G., Thurner, P.J., 2013. Load-bearing in cortical 395 bone microstructure: Selective stiffening and heterogeneous strain distribution at the lamellar 396 level. J Mech Behav Biomed Mater 17, 152-165.

397 Katsamenis, O.L., Jenkins, T., Thurner, P.J., 2015. Toughness and damage susceptibility in 398 human cortical bone is proportional to mechanical inhomogeneity at the osteonal-level. Bone 76, 399 158-168.

400 Milovanovic, P., Rakocevic, Z., Djonic, D., Zivkovic, V., Hahn, M., Nikolic, S., Amling, M., 401 Busse, B., Djuric, M., 2014. Nano-structural, compositional and micro-architectural signs of 402 cortical bone fragility at the superolateral femoral neck in elderly hip fracture patients vs. healthy 403 aged controls. Experimental gerontology 55, 19-28.

404 Misof, B.M., Patsch, J.M., Roschger, P., Muschitz, C., Gamsjaeger, S., Paschalis, E.P., Prokop, 405 E., Klaushofer, K., Pietschmann, P., Resch, H., 2014. Intravenous treatment with ibandronate 
normalizes bone matrix mineralization and reduces cortical porosity after two years in male osteoporosis: a paired biopsy study. J Bone Miner Res 29, 440-449.

408 Norman, T.L., Yeni, Y.N., Brown, C.U., Wang, Z., 1998. Influence of microdamage on fracture 409 toughness of the human femur and tibia. Bone 23, 303-306.

410 O’Brien, F.J., Taylor, D., Lee, T.C., 2003. Microcrack accumulation at different intervals during 411 fatigue testing of compact bone. J Biomech 36, 973-980.

412 Otsu, N., 1979. A Threshold Selection Method from Gray-Level Histograms. IEEE Transactions 413 on Systems, Man, and Cybernetics 9, 62-66.

414 Peterlik, H., Roschger, P., Klaushofer, K., Fratzl, P., 2006. From brittle to ductile fracture of 415 bone. Nat Mater 5, 52-55.

416 Phelps, J.B., Hubbard, G.B., Wang, X., Agrawal, C.M., 2000. Microstructural heterogeneity and 417 the fracture toughness of bone. J Biomed Mater Res 51, 735-741.

418 Poundarik, A.A., Diab, T., Sroga, G.E., Ural, A., Boskey, A.L., Gundberg, C.M., Vashishth, D., 419

420 Poundarik, A.A., Wu, P.C., Evis, Z., Sroga, G.E., Ural, A., Rubin, M., Vashishth, D., 2015. A 421

Roschger, P., Paschalis, E.P., Fratzl, P., Klaushofer, K., 2008. Bone mineralization density distribution in health and disease. Bone 42, 456-466.

Seref-Ferlengez, Z., Kennedy, O.D., Schaffler, M.B., 2015. Bone microdamage, remodeling and bone fragility: how much damage is too much damage? Bonekey Rep 4, 644.

Shigdel, R., Osima, M., Ahmed, L.A., Joakimsen, R.M., Eriksen, E.F., Zebaze, R., Bjornerem, A., 2015. Bone turnover markers are associated with higher cortical porosity, thinner cortices, and larger size of the proximal femur and non-vertebral fractures. Bone 81, 1-6.

429 Tai, K., Dao, M., Suresh, S., Palazoglu, A., Ortiz, C., 2007. Nanoscale heterogeneity promotes energy dissipation in bone. Nat Mater 6, 454-462.

431 Tang, S.Y., Vashishth, D., 2011. The relative contributions of non-enzymatic glycation and 432 cortical porosity on the fracture toughness of aging bone. J Biomech 44, 330-336.

433 Thurner, P.J., Katsamenis, O.L., 2014. The role of nanoscale toughening mechanisms in 434 osteoporosis. Curr Osteoporos Rep 12, 351-356.

435 Tommasini, S.M., Nasser, P., Hu, B., Jepsen, K.J., 2008. Biological co-adaptation of 436 morphological and composition traits contributes to mechanical functionality and skeletal 437 fragility. J Bone Miner Res 23, 236-246.

438 Ural, A., Mischinski, S., 2013. Multiscale modeling of bone fracture using cohesive finite 439 elements. Eng Fract Mech 103, 141-152. 
440 Ural, A., Vashishth, D., 2007. Effects of intracortical porosity on fracture toughness in aging human bone: a microCT-based cohesive finite element study. J Biomech Eng 129, 625-631.

442 Ural, A., Vashishth, D., 2014. Hierarchical perspective of bone toughness - from molecules to 443 fracture. International Materials Reviews 59, 245-263.

444 Wachter, N.J., Krischak, G.D., Mentzel, M., Sarkar, M.R., Ebinger, T., Kinzl, L., Claes, L., 445 Augat, P., 2002. Correlation of bone mineral density with strength and microstructural 446 parameters of cortical bone in vitro. Bone 31, 90-95.

447 Wang, M., Gao, X., Abdel-Wahab, A., Li, S., Zimmerman, E.A., Riedel, C., Busse, B., 448 Silberschmidt, V., 2015. Effect of micromorphology of cortical bone tissue on crack propagation 449 under dynamic loading. EPJ Web of Conferences 94, 03005.

450 Yao, H., Dao, M., Carnelli, D., Tai, K., Ortiz, C., 2011. Size-dependent heterogeneity benefits the 451 mechanical performance of bone. J Mech Phys Solids 59, 64-74.

452 Yeni, Y.N., Brown, C.U., Wang, Z., Norman, T.L., 1997. The influence of bone morphology on 453 fracture toughness of the human femur and tibia. Bone 21, 453-459.

454 Zebaze, R.M., Libanati, C., Austin, M., Ghasem-Zadeh, A., Hanley, D.A., Zanchetta, J.R., 455 Thomas, T., Boutroy, S., Bogado, C.E., Bilezikian, J.P., Seeman, E., 2014. Differing effects of 456 denosumab and alendronate on cortical and trabecular bone. Bone 59, 173-179.

457 Zioupos, P., 2001. Accumulation of in-vivo fatigue microdamage and its relation to 458 biomechanical properties in ageing human cortical bone. J Microsc 201, 270-278.

459 Zioupos, P., Gresle, M., Winwood, K., 2008. Fatigue strength of human cortical bone: age, 460 physical, and material heterogeneity effects. J Biomed Mater Res A 86, 627-636.

461 Zoehrer, R., Roschger, P., Paschalis, E.P., Hofstaetter, J.G., Durchschlag, E., Fratzl, P., Phipps, 462 R., Klaushofer, K., 2006. Effects of 3- and 5-year treatment with risedronate on bone 463 mineralization density distribution in triple biopsies of the iliac crest in postmenopausal women. $\mathrm{J}$ 464 Bone Miner Res 21, 1106-1112. 


\section{Figure legends}

Figure 1: Study design. (A) Single-edge notch beam specimens were machined from the femoral mid-shaft. The notch region was scanned with $\mu \mathrm{CT}$ to image porosity prior to mechanical testing. (B) Following fracture toughness testing, a cross-section was cut close to the fracture line,

polished, and mounted on a stub with standard materials for calibration. (C) qBEI images (in gray levels) of bone from young (23-year-old, left) and old (96-year-old, right) donors.

Figure 2: Characterization of cortical porosity from qBEI images. (A) Original image from a 47 years old female donor. (B) Porosity mask: black pixels include vascular and lacunar porosity. (C) Voronoi diagrams (red) are used to quantify the spatial distribution of vascular porosity.

Figure 3: Characterization of the distribution of mineralization from qBEI images. (A) Original image from a 24-year-old male donor. (B) Histogram of gray-levels in the qBEI images provides BSEpeak, the most frequent gray value, and BSEwidth, the width of the distribution, a measure of the overall heterogeneity in mineralization at the scale of the sample. (C) Experimental variogram describes the local heterogeneity in mineralization over a fixed length scale of $250 \mu \mathrm{m}$.

Figure 4: A sub-region $\left(1.5 \times 1.5 \mathrm{~mm}^{2}\right)$ was obtained from the center of the qBEI image. (A) Enhancing the contrast of the qBEI image facilitated the visualization of the boundaries between osteonal and interstitial tissues based on gray levels. (B) Resulting segmentation distinguished between pores (black), osteonal (gray) and interstitial (white) tissue. 
Figure 5: 3D bar graphs representing fracture toughness properties $\left(\mathrm{K}_{\text {init }}\right.$ on the left, $\mathrm{J}$ on the right) as a function of vascular porosity and osteonal area fraction. Simple linear regressions are plotted in the background for each variable. 


\section{Tables}

Table 1: Significant Pearson's correlation coefficients and corresponding p-values calculated from bootstrapped data.

\begin{tabular}{|c|c|c|c|c|c|c|c|c|c|}
\hline & \multirow[b]{2}{*}{ Age } & \multicolumn{3}{|c|}{ Porosity } & \multicolumn{4}{|c|}{ Mineralization } & \multirow{2}{*}{$\begin{array}{c}\text { Microstructure } \\
\text { Osteon area } \\
\text { fraction } \\
(\text { OstAr })\end{array}$} \\
\hline & & $\begin{array}{l}\text { Lacunar } \\
\text { porosity } \\
\text { (LacPor) }\end{array}$ & $\begin{array}{l}\text { Vascular } \\
\text { porosity } \\
\text { (VasPor) }\end{array}$ & $\begin{array}{c}\text { Pore } \\
\text { clustering } \\
(\text { VORcv) }\end{array}$ & $\begin{array}{c}\text { Degree of } \\
\text { mineralization } \\
\text { (BSEpeak) }\end{array}$ & $\begin{array}{l}\text { Bulk } \\
\text { heterogeneity } \\
(B S E \text { width })\end{array}$ & $\begin{array}{c}\text { Local } \\
\text { heterogeneity } \\
(\text { sill })\end{array}$ & $\begin{array}{c}\text { Inters./Osteon } \\
\text { heterogeneity } \\
\text { (IOratio) }\end{array}$ & \\
\hline Age & - & $\begin{array}{l}\mathbf{- 0 . 4 3} \\
0.002\end{array}$ & $\begin{array}{c}\mathbf{0 . 3 3} \\
0.039\end{array}$ & $\begin{array}{c}\mathbf{0 . 3 9} \\
0.004\end{array}$ & $\begin{array}{c}\mathrm{ns}^{\mathrm{a}} \\
0.346\end{array}$ & $\begin{array}{l}-0.27 \\
0.073\end{array}$ & $\begin{array}{c}\mathrm{ns} \\
0.432\end{array}$ & $\begin{array}{l}\mathbf{- 0 . 3 5} \\
0.011\end{array}$ & $\begin{array}{c}\mathbf{- 0 . 4 5} \\
<0.001\end{array}$ \\
\hline$K_{\text {init }}$ & $\begin{array}{l}\mathbf{- 0 . 4 8} \\
<0.001\end{array}$ & $\begin{array}{c}\mathbf{0 . 3 3} \\
0.020\end{array}$ & $\begin{array}{l}\mathbf{- 0 . 6 5} \\
<0.001\end{array}$ & $\begin{array}{l}\mathbf{- 0 . 5 9} \\
<0.001\end{array}$ & $\begin{array}{c}\mathrm{ns} \\
0.575\end{array}$ & $\begin{array}{c}\mathrm{ns} \\
0.232\end{array}$ & $\begin{array}{l}\mathbf{- 0 . 4 1} \\
<0.001\end{array}$ & $\begin{array}{c}\mathrm{ns} \\
0.890\end{array}$ & $\begin{array}{c}\mathbf{0 . 4 4} \\
<0.001\end{array}$ \\
\hline$K_{\text {grow }}$ & $\begin{array}{l}\mathbf{- 0 . 4 1} \\
0.010\end{array}$ & $\begin{array}{c}\mathrm{ns} \\
0.378\end{array}$ & $\begin{array}{l}-22.4 \\
0.063\end{array}$ & $\begin{array}{l}\mathbf{- 0 . 3 1} \\
0.006\end{array}$ & $\begin{array}{c}\mathrm{ns} \\
0.144\end{array}$ & $\begin{array}{c}\mathrm{ns} \\
0.805\end{array}$ & $\begin{array}{c}\mathrm{ns} \\
0.579\end{array}$ & $\begin{array}{c}\mathrm{ns} \\
0.207\end{array}$ & $\begin{array}{c}\mathbf{0 . 3 6} \\
0.020\end{array}$ \\
\hline$J$ & $\begin{array}{l}\mathbf{- 0 . 3 6} \\
0.001\end{array}$ & $\begin{array}{l}0.23 \\
0.071\end{array}$ & $\begin{array}{l}\mathbf{- 0 . 3 8} \\
<0.001\end{array}$ & $\begin{array}{l}\mathbf{- 0 . 3 7} \\
<0.001\end{array}$ & $\begin{array}{c}\mathrm{ns} \\
0.165\end{array}$ & $\begin{array}{c}\mathrm{ns} \\
0.510\end{array}$ & $\begin{array}{l}\mathbf{- 0 . 2 3} \\
0.041\end{array}$ & $\begin{array}{c}\mathrm{ns} \\
0.174\end{array}$ & $\begin{array}{c}\mathbf{0 . 4 2} \\
<0.001\end{array}$ \\
\hline
\end{tabular}

${ }^{a}$ ns indicates that the correlation is not statistically significant. 
Table 2: Best-fit multivariate linear combinations of parameters explaining the variance in the fracture toughness of human cortical bone obtained upon running multiple linear regressions using backward stepwise elimination.

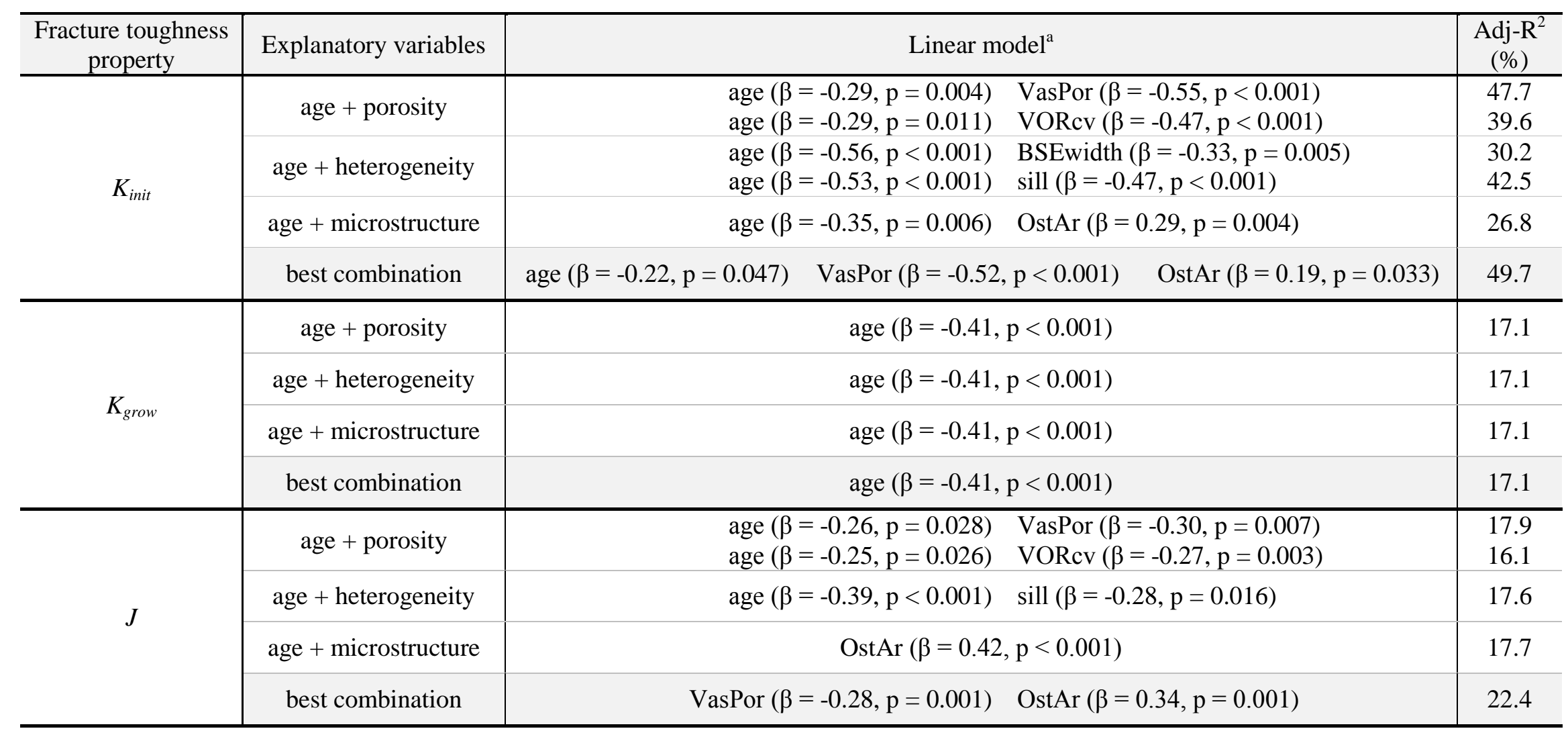

${ }^{\mathrm{a}}$ None of the interaction terms were significant.

${ }^{\mathrm{b}} \beta$ is the standardized coefficients from the general linear model. 
FigureV

Figure 1

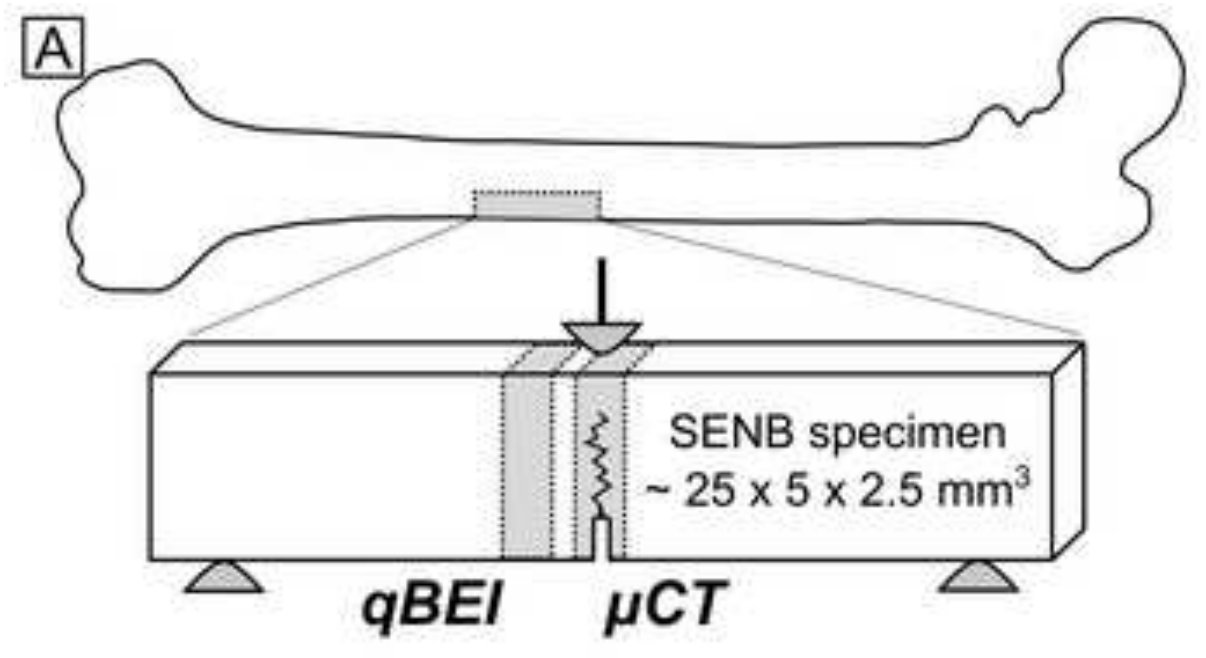

B
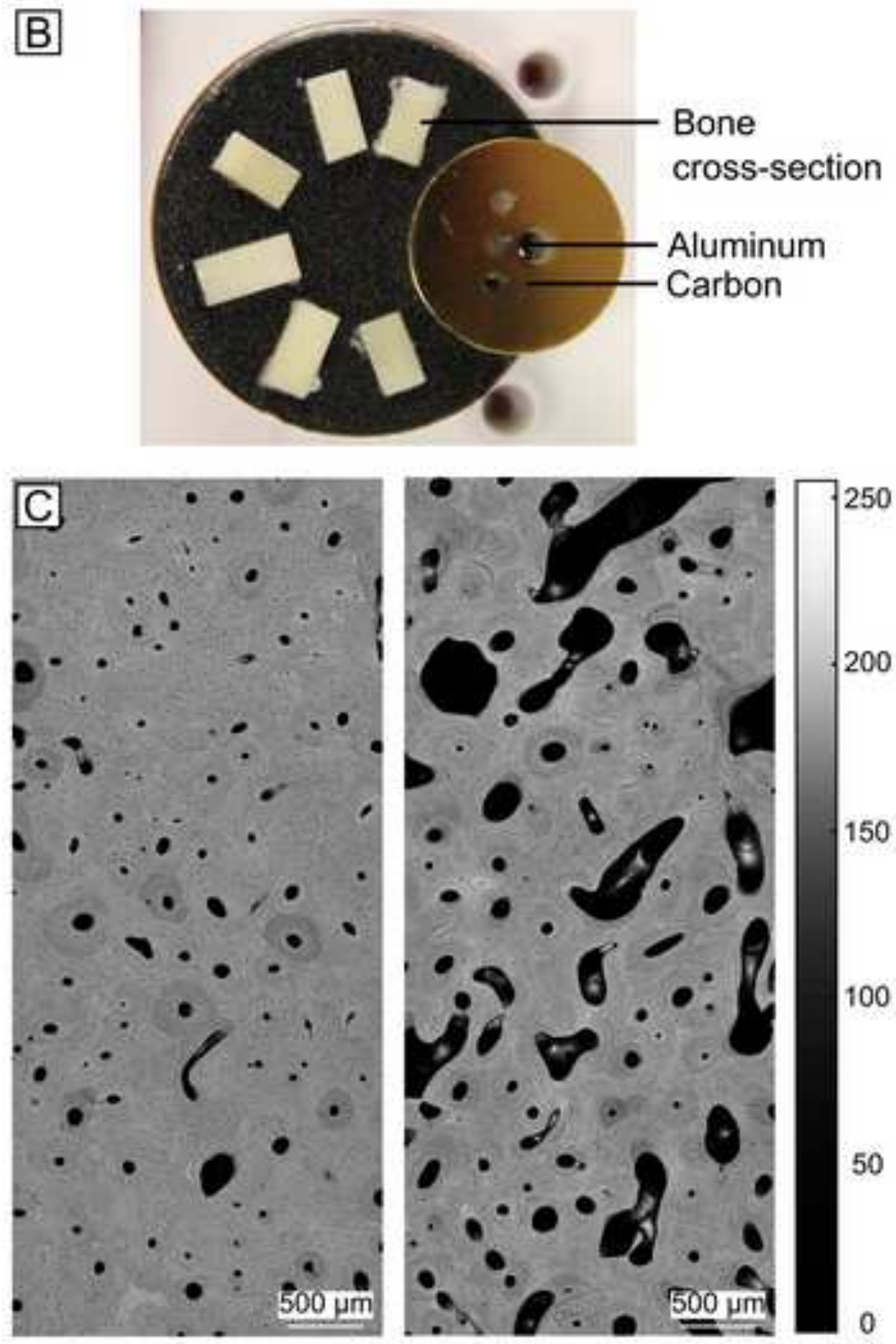

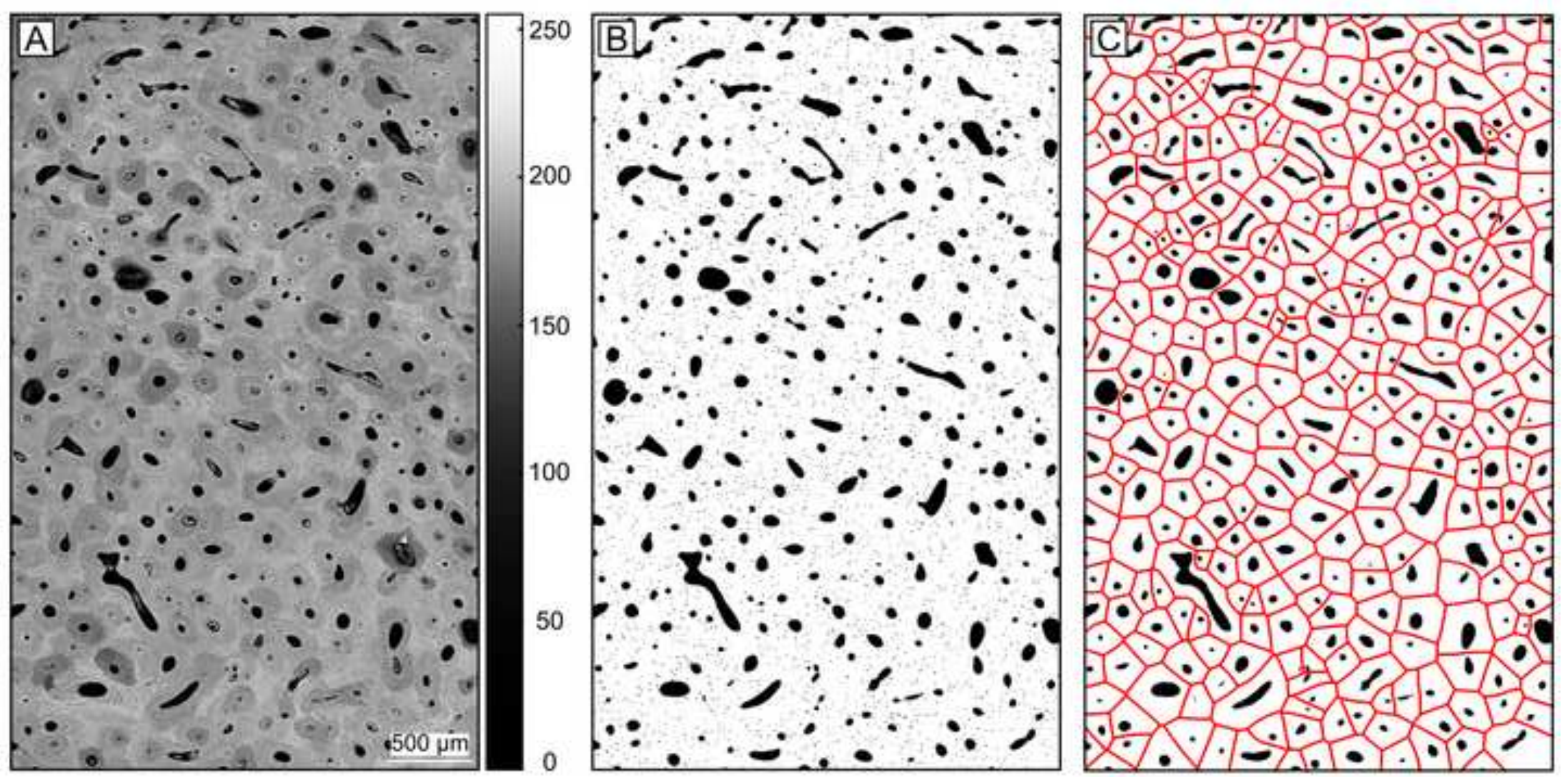

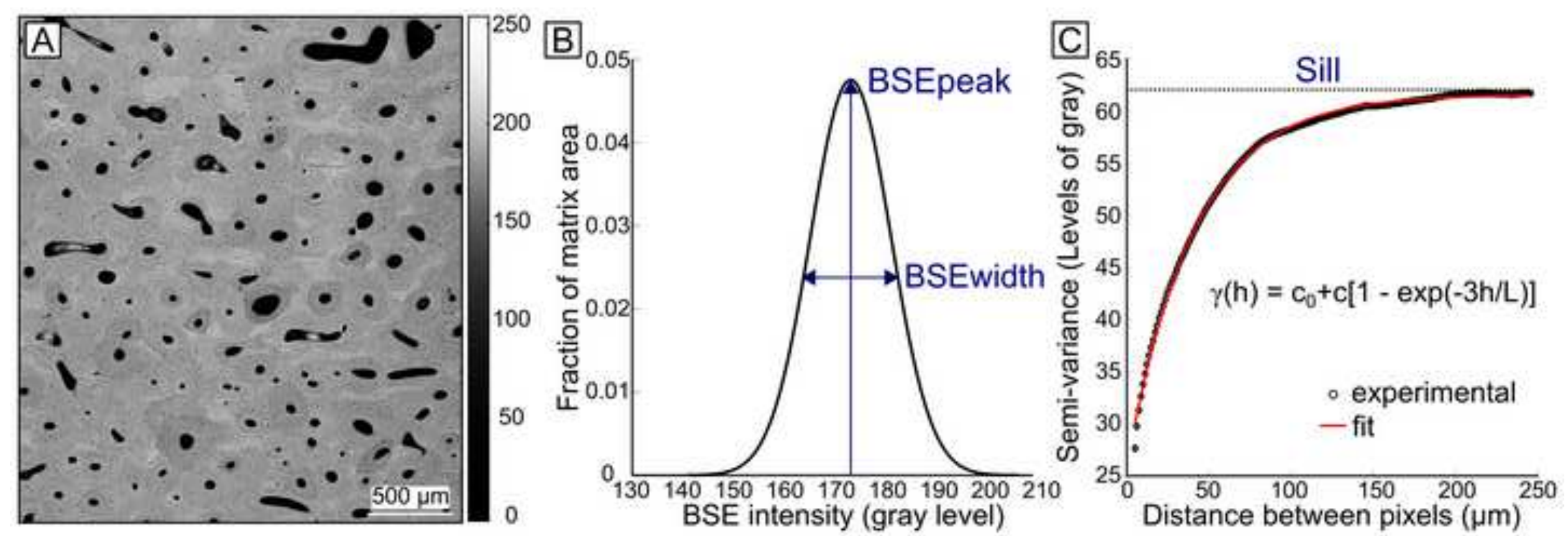

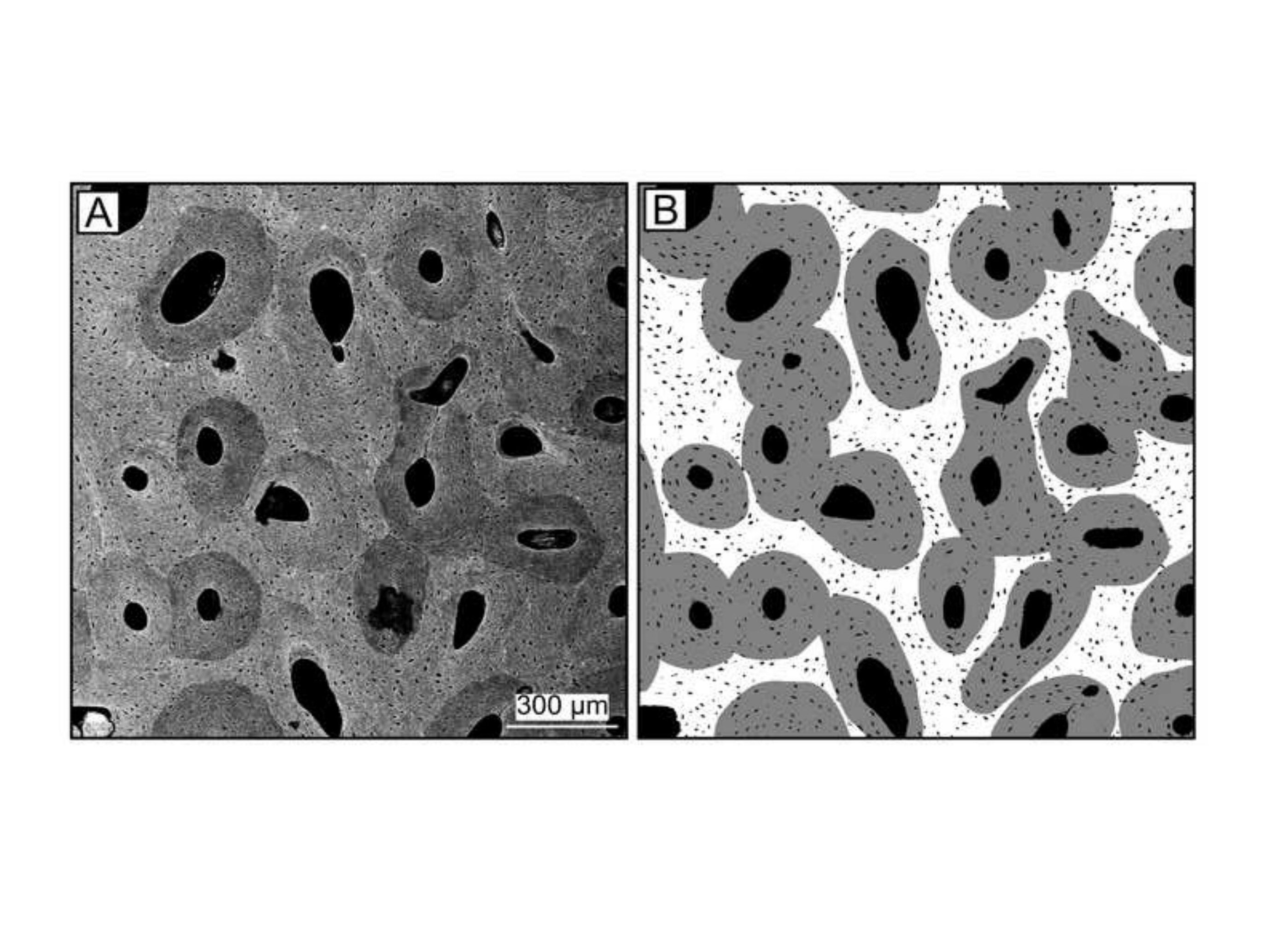

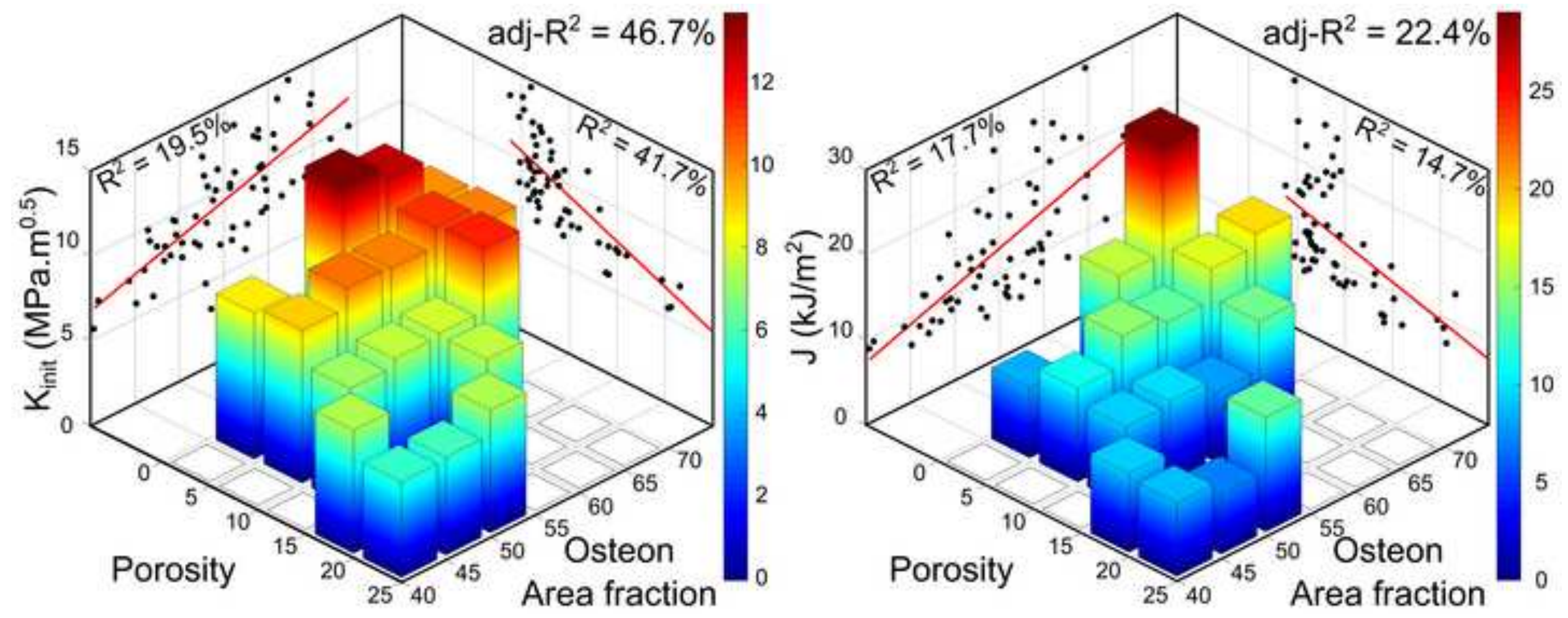